\title{
Bottleneck Removal of Paclitaxel Biosynthetic Pathway By Overexpression of DBTNBTGene Under Methyl- $\beta$ - Cyclodextrin and Coronatine Elicitation in Taxus Baccata L.
}

\author{
Kimia Kashani \\ Tarbiat Modares University \\ Mohammad Sadegh Sabet ( $\square$ ms.sabet@modares.ac.ir) \\ Tarbiat Modares University \\ Mokhtar Jalali Javaran \\ Tarbiat Modares University \\ Ahmad Moieni \\ Tarbiat Modares University
}

\section{Research Article}

Keywords: Taxus baccata L., Taxaceae, Transcription profiling, Cell-associated/ Extracellular paclitaxel, Metabolic engineering

Posted Date: November 12th, 2021

DOI: https://doi.org/10.21203/rs.3.rs-1032537/v1

License: (c) (1) This work is licensed under a Creative Commons Attribution 4.0 International License. Read Full License

Version of Record: A version of this preprint was published at Plant Cell, Tissue and Organ Culture (PCTOC) on March 28th, 2022. See the published version at https://doi.org/10.1007/s11240-022-022794. 


\section{Abstract}

Paclitaxel is a highly functionalized diterpenoid that is broadly used for the treatment of several cancer types. This valuable specialized metabolite naturally exists in the inner bark of Taxus species in low amounts. The limited-scale production of paclitaxel in Taxus cell cultures has necessitated the use of several elicitors. Recently, methyl- $\beta$-cyclodextrin (CD) and coronatine (COR) have been considered to be highly effective elicitors in producing plant specialized metabolites. Given the limited production of paclitaxel due to the rate limiting enzymes' function, bottleneck removal is conducive to the production of more significant amounts of paclitaxel. In the present study, the full length of DBTNBT coding sequence (CDS), as one of the paclitaxel pathway bottlenecks, was integrated downstream of the CaMV 35S promoter (pCAMBIA1304-DBTNBT) and transiently expressed in Taxus baccata leaves via Agrobacterium tumefaciens and vacuum infiltration method. Paclitaxel production and the expression level of several involved genes were evaluated through different treatments. The transient overexpression of the DBTNBT gene, associated with dual elicitation, resulted in 7.4-fold more paclitaxel production compared with the no-inoculation/no-elicitation control. These ratios were 2.1 and 1.8 in the $C D+C O R$ and PCAM treatments, respectively. Among $T 13 a H, T 14 \beta H, D B A T, B A P T, D B T N B T$, and $A B C$ genes, the most increased expression level belonged to the $D B T N B T$ gene, followed by $A B C$ and $B A P T$ genes. It seems as though in the near future, bottleneck removal could be used on a large scale in Taxus metabolic engineering, resulting in the relative removal of some other bottlenecks and an increase in the final paclitaxel production.

\section{Introduction}

Plants are good sources of pharmaceutical compounds, particularly anticancer ones. Certain plant-based anticancer drugs have been introduced, such as paclitaxel (Taxol®), vinblastine, vincristine, camptothecin, podophyllotoxin, and ajmalicine. Among these drugs, paclitaxel and its related compounds have attracted a great deal of attention owing to their high efficiency in treating a wide range of cancers (Cragg and Newman 2005). Paclitaxel has a high anticancer activity because of its unique tumorsuppressing mechanism through which it prevents the mitosis by stabilizing microtubules against depolymerization (Srivastava et al. 2005).

Despite clinical success (Zhu and Chen 2019), the most critical problem associated with paclitaxel production is providing sufficient amounts of this pharmaceutical compound (Sabzehzari and Naghavi 2019; Salehi et al. 2019). Different species of the yew tree (Taxus spp.) have been identified as the most important natural resources of taxanes. Roughly 0.0001 to $0.0017 \%$ of the Taxus bark in dry weight scale is paclitaxel. Due to its scarcity, slow growth rate, low concentration, and the existence of more than 400 similar compounds, paclitaxel extraction and purification procedures are not cost-effective and can destroy these natural reservoirs in the long run (Jaziri et al. 1996; Sabater-Jara et al. 2010).

Currently, chemical synthesis, semi-synthesis, production by endophytes, Taxus spp., and Corylus avellana cell suspension cultures are proposed for paclitaxel production. Among these methods, cell 
suspension culture is one of the most beneficial ones owing to being optimal, renewable, and adaptable, providing the possibility to use elicitors to increase the final product (Jennewein et al. 2001; Pyo et al. 2005).

Since the 1990s, abiotic and biotic elicitors, alone or in combination, have been widely used to improve the production of bioactive metabolites in cell suspension cultures (Chandran et al. 2020; Malik et al. 2011; Onrubia et al. 2013; Satish et al. 2020). Methyl- $\beta$-cyclodextrin (CD) is a circular oligosaccharide that acts as an elicitation agent for producing specialized metabolites in plant cell suspension cultures (Almagro and Pedreño 2020; Bru et al. 2006; Lijavetzky et al. 2008; Zamboni et al. 2009). It was previously proven that the combined use of methyl jasmonate (MeJA) and CD was more effective than the use of MeJA alone in increasing taxane production (Sabater-Jara et al. 2014). Coronatine (COR) is a bacterial blight phytotoxin produced by several pathovars of Pseudomonas syringae (Bender et al. 1999). COR has gained significant attention on account of its potential role in plant growth regulation and as a potent elicitor by triggering the jasmonate signaling pathway (Zhao et al. 2003). This phytotoxin is a molecular mimic of the isoleucine jasmonic acid (JA-lle), the intracellular switch of the jasmonate pathway (Cusido et al. 2014).

Elicitors are believed to enhance the paclitaxel production up to a certain extent (Exposito et al. 2010; Ho et al. 2005), probably because of the paclitaxel toxicity for producer cells, which leads to the conversion of downstream genes to the bottlenecks in a way that paclitaxel be produced to the extent that it does not harm the cell viability (Kashani et al. 2018). The accumulation of paclitaxel inside the cell causes feedback inhibition, degradation of the final product (Mubeen et al. 2019), and feedback repression effect on the upstream genes involved in the paclitaxel biosynthetic pathway (Cusido et al. 2014); therefore, identifying and removing bottlenecks can be an appropriate approach to increasing the production of paclitaxel.

Paclitaxel is obtained after five steps: 1) providing the precursor of terpenoid compounds from the primary metabolism, 2) cyclizing the geranylgeranyl diphosphate, 3) oxygenation by cytochrome P450dependent hydroxylases, 4) acylation, 5) conjugation of side-chain, followed by the last steps of paclitaxel biosynthetic pathway. In this pathway, $\mathrm{T13aH}$ is a cytochrome P450-dependent hydroxylase that forms taxa-4(20), 11(12)-dien-5a-13a-diol. $T 14 \beta H$ is responsible for the formation of taxa-4(20),

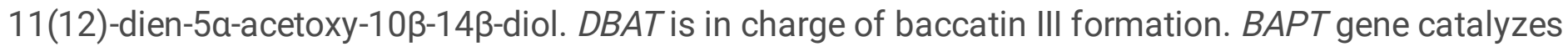
the conjugation of $\beta$-phenylalanoyl-CoA side-chain to the baccatin III, and the DBTNBT gene is responsible for benzoyl-CoA conjugation to 3'-N-debenzoyl-2'-deoxytaxol and yielding the final product (Malik et al. 2011). A putative ATP-binding cassette $(A B C)$ was found to play an essential role in taxane excretion (Sabater-Jara et al. 2014) (Fig. 1).

Metabolic engineering may be a robust approach to increasing paclitaxel production in Taxus platforms. Previous studies have shown that in the paclitaxel biosynthetic pathways, the genes encoding the downstream enzymes appear to control the limiting biosynthetic steps. The DBTNBT gene is the last 
transferase in paclitaxel biosynthetic pathway, introduced as a bottleneck gene in $T$. baccata under the dual elicitation of CD and COR (Kashani et al. 2018).

Despite the overexpression of the genes involved in the paclitaxel biosynthetic pathways, elicitation is still required for the maximum paclitaxel production by the producer cells (Exposito et al. 2010; Ho et al. 2005). To the best of our knowledge, no research has ever been conducted on the effects of bottleneck removal via $D B T N B T$ gene overexpression in $T$. baccata to enhance the amounts of paclitaxel production. With that in mind, the present study aimed to assess the impacts of DBTNBT overexpression on cellassociated and extracellular paclitaxel amounts and the transcriptional profiles of $T 13 a H, T 14 \beta H, D B A T$, $B A P T, D B T N B T$, and $A B C$ genes under the elicitation of $\mathrm{CD}$ and $\mathrm{COR}$. The results of this study underscore the importance of bottleneck removal regarding paclitaxel biosynthetic pathway; this approach will be applicable in the forthcoming future, particularly in regard to $T$. baccata metabolic engineering.

\section{Materials And Methods}

\section{1. Construction of pCAMBIA-DBTNBT vector}

A chimeric fragment, including the 5 ' UTR of DBTNBT gene in T. media (AY563629.1), the coding region of DBTNBT gene (AF466397.1, 1326 bp), and the 3' UTR of the cowpea mosaic virus (GQ497234.1) (Supplementary material- Fig. 1 and Fig. 2) was synthesized by Shinegene company (China). This fragment was integrated between the EcoRI and Sphl restriction sites in the pUC57 vector (pUC57DBTNBT). Plasmid extraction and double digestion reactions of pCAMBIA1304 (AF234300.1) and pUC57$D B T N B T$ vectors were conducted using Spel/BstEll restriction enzymes. The desired fragments (the backbone of the pCAMBIA1304 vector (9802 bp) and the target fragment of the DBTNBT gene along with its UTRs and designed restriction sites (1584 bp)) were purified and the ligation reaction was carried out with a ratio of 3 (vector) to 1 (insert). The ligation reaction components were $13 \mathrm{ng} \mathrm{\mu l}^{-1}$ of pCAMBIA1304 backbone, $10 \mathrm{ng} \mathrm{Hl}^{-1}$ of insert, T4 buffer (1x), and $0.66 \mathrm{U} \mathrm{\mu l}^{-1} \mathrm{~T} 4$ ligase (Fermentas) to a final volume of $30 \mu \mathrm{l}$. The reaction tube was incubated at $22^{\circ} \mathrm{C}$ for $1 \mathrm{~h}$, followed by $4^{\circ} \mathrm{C}$ for $16-18 \mathrm{~h}$.

Sequencing carried out by South Korean Bioneer Corporation through the use of CA+2 and NOS primers (Supplementary Material- Table 1) and double/ mono digestion reactions were done to confirm the accuracy of the fragment. 
Table 1

Inoculation, elicitation, and perforation conditions of treatments

\begin{tabular}{|c|c|c|c|c|}
\hline Treatment Name & $\begin{array}{l}\text { Inoculation } \\
\text { Condition }\end{array}$ & $\begin{array}{l}\text { Elicitation with } \mathrm{CD}(50 \mathrm{mN} \\
\mu \mathrm{M})\end{array}$ & and COR (1 & $\begin{array}{l}\text { Leave } \\
\text { Perforation with } \\
\text { Needle }\end{array}$ \\
\hline $\begin{array}{l}\text { no-inoculation/no- } \\
\text { elicitation control }\end{array}$ & \multicolumn{2}{|l|}{-} & - & - \\
\hline $\mathrm{CD}+\mathrm{COR}$ & \multicolumn{2}{|l|}{-} & 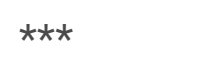 & $\star \star \star$ \\
\hline pCAM & \multicolumn{2}{|c|}{$\begin{array}{l}\text { with Agrobacterium harboring } \\
\text { pCAMBIA1304 vector (for } 2 \text { h using } \\
\text { vacuum infiltration method) }\end{array}$} & - & $\star \star \star$ \\
\hline pCAM-DBTNBT/CD+COR & \multicolumn{3}{|c|}{$\begin{array}{l}\text { with Agrobacterium harboring } \\
\text { pCAMBIA1304-DBTNBT vector (for } 2 \mathrm{~h} \\
\text { using vacuum infiltration method) }\end{array}$} & $\star \star \star *$ \\
\hline \multicolumn{5}{|c|}{$\begin{array}{l}\text { no-inoculation/no-elicitation control; } C D+C O R \text {, no inoculation- elicitation with methyl- } \beta \text { - cyclodextrin } \\
\text { (CD) and coronatine (COR); pCAM, inoculation with Agrobacterium harboring pCAMBIA1304 vector- } \\
\text { no elicitation; pCAM-DBTNBT/CD+COR, inoculation with Agrobacterium harboring pCAMBIA1304- } \\
\text { DBTNBT vector- elicitation with methyl- } \beta \text { - cyclodextrin (CD) and coronatine (COR) }\end{array}$} \\
\hline
\end{tabular}

\section{2. Bacterial transformation and confirmation}

Escherichia coli (DH5a) competent cells were produced (Green and Rogers 2013) and into which the vectors were transformed (Sambrook and Russell 2001). For bacterial transformation, after transferring the ligation reaction product to the $E$. coli (DH5a) competent cells, the tube was placed in an ice container for $30 \mathrm{~min}$ followed by incubation at $42^{\circ} \mathrm{C}$ for $60 \mathrm{~s}$ and being put in an ice container for $5 \mathrm{~min} .800 \mu \mathrm{l}$ of S.O.C. medium (tryptone $2 \%$, yeast extract $0.5 \%, \mathrm{NaCl} 0.01 \mathrm{M}, \mathrm{MgSO}_{4} 0.01 \mathrm{M}, \mathrm{KCl} 0.0025 \mathrm{M}^{2} \mathrm{MgCl}_{2} 0.01$ $\mathrm{M}$, and glucose $0.02 \mathrm{M})$ was added to the tubes. The tubes were incubated in a shaker incubator $\left(37^{\circ} \mathrm{C}\right.$, $180 \mathrm{rpm}$ ) for $80 \mathrm{~min} .100 \mu \mathrm{l}$ of tube content was spread on a petri dish containing LB agar medium with $50 \mu \mathrm{g} \mathrm{ml}^{-1}$ of kanamycin. Petri dishes were incubated overnight at $37^{\circ} \mathrm{C}$.

The pCAMBIA-DBTNBT and pCAMBIA1304 vectors were transformed into the Agrobacterium tumefaciens (LBA4404) (Rhizobiaceae) competent cells prepared according to the calcium chloride protocol (Sambrook and Russell 2001).

The transformation of E. coli and Agrobacterium were confirmed using colony PCR, in which Ampliqon Master Mix $1 \mathrm{x}$ with $1.5 \mathrm{mM}$ of $\mathrm{MgCl}_{2}$ (containing Taq DNA Polymerase), $\mathrm{F}$ (forward) and $\mathrm{R}$ (reverse) primers (Supplementary material- Table 1 ) (each with a final concentration of $266 \mu \mathrm{M}$ ), and a colony of bacteria grown in the culture medium containing selective antibiotics were used. The PCR program was as follows: $94^{\circ} \mathrm{C}, 5 \mathrm{~min} ; 35$ cycles of $94^{\circ} \mathrm{C}, 30 \mathrm{~s}$; annealing, $50 \mathrm{~s} ; 72^{\circ} \mathrm{C}, 120 \mathrm{~s}$, and $72^{\circ} \mathrm{C}, 10 \mathrm{~min}$

\section{3. Plant transformation}

The leaves of the perennial yew tree (T. baccata), located in the Botanic Garden of Tehran University, were used as the primary plant material for gene transformation. Vacuum infiltration method (using 
Agrobacteria containing PCAMBIA-DBTNBT and pCAMBIA1304 vectors) was utilized for the transient expression of DBTNBT and GFP-GUS genes in T. baccata leaves.

Overnight culture of Agrobacterium and centrifugation $\left(1600 \mathrm{~g}, 15 \mathrm{~min}, 4^{\circ} \mathrm{C}\right.$ ) were further performed, and the bacterial pellet was re-suspended in an induction medium $\left(\mathrm{pH} \mathrm{5.2)}\right.$ and incubated at $28^{\circ} \mathrm{C}$. The final optical density (OD) at $600 \mathrm{~nm}$ was $0.6-0.8$. The ingredients of this medium were as follows: B5 medium salts except macro-elements $(1 \mathrm{x})$, vitamins $(2 \mathrm{x})$, sucrose $(0.5 \%)$, mannitol $(0.01 \mathrm{M})$, glucose $(0.1 \mathrm{M})$, sorbitol $(0.1 \mathrm{M})$, fructose $(1 \mathrm{M}), \mathrm{KNO}_{3}\left(2500 \mathrm{mg} \mathrm{l}^{-1}\right)$, myo-inositol $\left(100 \mathrm{mg} \mathrm{l}^{-1}\right)$, ascorbic acid $\left(100 \mathrm{mg} \mathrm{I}^{-1}\right)$, naphthalene acetic acid $\left(2 \mathrm{mg} \mathrm{l}^{-1}\right)$, kinetin $\left(0.1 \mathrm{mg} \mathrm{l}^{-1}\right)$, casein hydrolyzate $\left(1000 \mathrm{mg} \mathrm{l}^{-1}\right)$, and acetosyringone $(0.2 \mathrm{mM})$. The treatments were no-inoculation/no-elicitation control, CD+COR, pCAM, and pCAM-DBTNBT/CD+COR (Table 1). The leaves were placed in sterilized distilled water containing CD (50 $\mathrm{mM})$ and COR $(1 \mu \mathrm{M})$ while gently shaken for elicitation. (Singh et al. 2020). The leaves in pCAM and pCAM-DBTNBT/CD+COR treatments were incubated for $16-18 \mathrm{~h}$ at $28^{\circ} \mathrm{C}$ in dark.

\section{4. Paclitaxel extraction and determination}

Paclitaxel was extracted from the leaves (Rahpeyma et al. 2015), Afterwards, the freeze-dried leaves were weighted, pulverized, and suspended in $4 \mathrm{ml}$ of HPLC grade methanol, followed by ultrasonication for 30 min and centrifugation at $1340 \mathrm{~g}$ for $15 \mathrm{~min}$ at $22^{\circ} \mathrm{C}$. The upper phase was transferred to a vacuum oven to remove the solvent. The extract was resuspended in dichloromethane/water $(1: 1, v / v)$ and centrifuged at $1340 \mathrm{~g}$ for $15 \mathrm{~min}$ at $22^{\circ} \mathrm{C}$. The lower phase (Dichloromethane) was isolated. Subsequently, vacuum evaporation was carried out. The remaining material was resuspended in $500 \mu \mathrm{l}$ of HPLC grade acetonitrile and filtered via the $0.22 \mu \mathrm{m}$ filters (Millipore) prior to high-performance liquid chromatography (HPLC) analysis.

The extracellular paclitaxel was extracted from the media (Onrubia. et al. 2013) with some modifications. $15 \mathrm{ml}$ of the medium was harvested 6,13, and 17 days after the elicitation time (Kashani et al. 2018), it was mixed with an equal volume of dichloromethane (DCM) and shaken for $2 \mathrm{~h}$, followed by lower-phase separation. The solvent was removed from the organic phase by being transferred to a vacuum oven. The remaining material was resuspended in $0.5 \mathrm{ml}$ of HPLC grade acetonitrile and filtered with the $0.22 \mu \mathrm{m}$ filters (Millipore) prior to being injected into HPLC instrument.

To determine paclitaxel concentration, an HPLC system (Waters 2695; USA) equipped with an RP C-18 column (KNAUER100-5 C18, $250 \times 4.6 \mathrm{~mm}$, Germany) was used and elution was carried out in a gradient system with acetonitrile/water (20: 80- 80: 20 during $60 \mathrm{~min}$ ) with a flow rate of $1 \mathrm{ml} \mathrm{min}^{-1}$. Paclitaxel was detected at $230 \mathrm{~nm}$ via a UV detector (PDA Waters 996, USA). The injection was performed using an autosampler injector equipped with a $100 \mu$ loop. The paclitaxel was identified by comparing the retention times with an authentic standard. To draw the calibration curve, the paclitaxel standard was used at 1.5, 3, 6, 12, and $24 \mathrm{ppm}$. Data acquisition and integration were performed with Millennium 32 software.

\section{5. RNA extraction, cDNA synthesis, and Real-Time PCR analysis}


The cDNA was synthesized using $1 \mu \mathrm{g}$ of total RNA extracted from the frozen leaves (Channuntapipat et al. 2001) and MMLV-RT (Thermo Fisher Scientific). EvaGreen Real-Time PCR master mix, diluted cDNA, and $100 \mu \mathrm{M}$ of $\mathrm{F}$ and $\mathrm{R}$ primers were utilized in a 96-well platform of BioRad (USA) instrument. The RealTime PCR parameters were as follows: $95^{\circ} \mathrm{C}$ for $15 \mathrm{~min}$ and 40 cycles at $95^{\circ} \mathrm{C}$ for $15 \mathrm{~s}, 60^{\circ} \mathrm{C}$ for $20 \mathrm{~s}$, and $72^{\circ} \mathrm{C}$ for $20 \mathrm{~s}$.

Gene-specific primers were designed employing Oligo 7 software (Supplementary material- Table 2), and the amplification efficiency of each primer pair was calculated using cDNA's serial dilutions (Supplementary material- Table 3). Primer pairs with efficiency ranges of $90-110 \%$ were included in the analysis. The obtained data were processed using BioRad CFX Manager software ver. 1.6 (BioRad, USA) and (1+Efficiency) ${ }^{-\Delta \Delta C t}$ formula (Livak and Schmittgen 2001). The relative expression levels were normalized with respect to the expression level of GAPDH as a reference gene compared to the noinoculation/no-elicitation control, $4 \mathrm{~h}$ after the elicitation time (reference value $=1$ ).

Table 2

The results of relative expression level evaluation, the highest relative expression level, and its related treatment and time

\begin{tabular}{|c|c|c|c|}
\hline $\begin{array}{l}\text { Gene } \\
\text { Name }\end{array}$ & $\begin{array}{l}\text { The Highest Relative } \\
\text { Expression Level }\end{array}$ & $\begin{array}{l}\text { Treatment of the Highest } \\
\text { Relative Expression Level }\end{array}$ & $\begin{array}{l}\text { Time of the Highest Relative } \\
\text { Expression Level }\end{array}$ \\
\hline $\mathrm{T} 13 \mathrm{aH}$ & 2.57 & $\mathrm{pCAM}-D B T N B T / \mathrm{CD}+\mathrm{COR}$ & $4 \mathrm{~h}$ after dual elicitation \\
\hline $\mathrm{T} 14 \beta \mathrm{H}$ & 0.66 & pCAM & $\begin{array}{l}16 \mathrm{~h} \text { after dual elicitation } \\
\text { time }\end{array}$ \\
\hline DBAT & 5.63 & $\mathrm{pCAM}-D B T N B T / \mathrm{CD}+\mathrm{COR}$ & $16 \mathrm{~h}$ after dual elicitation \\
\hline BAPT & 6.34 & $\mathrm{pCAM}-D B T N B T / C D+C O R$ & $16 \mathrm{~h}$ after dual elicitation \\
\hline DBTNBT & 13.93 & $\mathrm{pCAM}-D B T N B T / \mathrm{CD}+\mathrm{COR}$ & $24 \mathrm{~h}$ after dual elicitation \\
\hline$A B C$ & 13.04 & $\mathrm{pCAM}-D B T N B T / \mathrm{CD}+\mathrm{COR}$ & $16 \mathrm{~h}$ after dual elicitation \\
\hline \multicolumn{4}{|c|}{$\begin{array}{l}\text { pCAM, inoculation with Agrobacterium harboring pCAMBIA1304 vector- no elicitation; pCAM- } \\
D B T N B T / C D+C O R \text {, inoculation with Agrobacterium harboring pCAMBIA1304-DBTNBT vector- } \\
\text { elicitation with methyl- } \beta \text { - cyclodextrin (CD) and coronatine (COR) }\end{array}$} \\
\hline
\end{tabular}

\section{6. Statistical analysis}

Statistical analyses were performed using SPSS ver. 16 after ensuring the data normality. All the data were calculated as the average of at least two biological and two technical replicates \pm SE. Completely randomized design (CRD) and a factorial experiment in a completely randomized design (CRD) were applied to evaluate paclitaxel contents and gene expression levels. All the analyses were followed by LSD mean comparison tests ( $P$-value $<0.01)$.

\section{Results}

3. 1. Cloning and transformation of overexpression vector 
The transformation of pUC57-DBTNBT and pCAMBIA1304 into E. coli (DH5a) (Enterobacteriaceae) competent cells was confirmed using colony PCR reaction (Supplementary material- Fig. 3 and Fig. 4). The double digestion reactions with Spel/BstEll restriction enzymes confirmed the accuracy of pUC57$D B T N B T$ and pCAMBIA1304 vectors (Supplementary material- Fig. 5 and Fig. 6). The bacterial colonies harboring pCAMBIA1304-DBTNBT (pCAMBIA-DBTNBT) vector were confirmed using colony PCR reaction (Supplementary material- Fig. 7). Further validations on the vectors extracted from positive colonies were carried out via Spel/ BstEll (Supplementary material- Fig. 8), Xhol (Supplementary material- Fig. 9), and Sall (Supplementary material- Fig. 10) enzymes. In addition, the results of pCAMBIA-DBTNBT sequencing using CaMV $35 \mathrm{~S}(\mathrm{CA}+2)$ forward and NOS reverse primers verified the identity of the inserted sequence with the DBTNBT CDS of $T$. canadensis (AF466397.1). In this CDS, an ORF (1326 bp) was detected, which coded a 441-amino acid protein. Furthermore, the colony PCR confirmed the transformation of pCAMBIA-DBTNBT and pCAMBIA1304 vectors into the Agrobacterium competent cells (Supplementary material- Fig. 11 and Fig. 12).

\section{2. Production of total paclitaxel}

The highest amount of total and cell-associated paclitaxel $\left(140\right.$ and $118 \mu \mathrm{g} \mathrm{g}^{-1}$ ) belonged to the treatment of pCAM-DBTNBT/CD+COR 17 days after the elicitation (Fig. 2 and Supplementary materialFig. 13). The transient overexpression of the DBTNBT gene, associated with the dual elicitation, culminated in 7.4-fold more paclitaxel production compared to the no-inoculation/no-elicitation control. Among the investigated treatments (pCAM-DBTNBT/CD+COR, pCAM, CD+COR, and no-inoculation/noelicitation control), the highest increase in the total paclitaxel belonged to the pCAM-DBTNBT/CD+COR followed by $C D+C O R$ and $P C A M$, respectively. Moreover, the total amounts of cell-associated paclitaxel in all the treatments were higher than those of the extracellular ones. The pCAM-DBTNBT/CD+COR and $C D+C O R$ treatments resulted in more extracellular paclitaxel amounts on account of the increased secretion of paclitaxel caused by the function of CD (Sabater-Jara et al. 2014) and the prevention of paclitaxel degradation.

\section{3. Evaluation of gene expression}

The expression level of $T 13 a H, T 14 \beta H, D B A T, B A P T, D B T N B T$, and $A B C$ genes were evaluated in different treatments (pCAM-DBTNBT/CD+COR, pCAM, CD+COR, and no-inoculation/no-elicitation control). Based on the results, a significant difference was observed among pCAM-DBTNBT/CD+COR, $\mathrm{PCAM}, \mathrm{CD}+\mathrm{COR}$, and no-inoculation/no-elicitation control (Fig. 3 and Table 2).

Concerning the time-course expression profile of $T 13 a H$ (responsible for the formation of taxa-4(20), 11(12)-dien-5a-13a-diol), the highest increase in the expression level was observed in the PCAM and pCAM-DBTNBT/CD+COR with no significant differences in most of the investigated times and $C D+C O R$ ranked second (Fig. 3 and Table 2).

A remarkable feature in the expression level of the $T 14 \beta H$ gene (in charge of forming taxa-4(20), 11(12)-

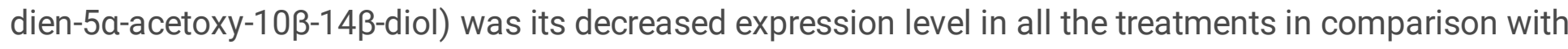


the no-inoculation/no-elicitation control. The highest reduction in the expression level of $T 14 \beta H$ belonged to $C D+C O R$ treatment, followed by pCAM-DBTNBT/CD+COR and pCAM treatments (Fig. 3 and Table 2).

Regarding the expression level of $D B A T$ gene (responsible for hydroxylation at the C10 position of the 10deacetylbaccatin), pCAM-DBTNBT/CD+COR ranked first among the treatments, followed by pCAM and CD+COR (Fig. 3 and Table 2).

Concerning the BAPT gene (in charge of catalyzing the conjugation of the $\beta$-phenylalanoyl-CoA side-chain to baccatin III), the highest increase in the expression level among the investigated treatments belonged to the pCAM-DBTNBT/CD+COR, followed by pCAM and CD+COR treatments, respectively (Fig. 3 and Table 2).

Compared to the no-inoculation/no-elicitation control, in the pCAM-DBTNBT/CD+COR, pCAM, and $\mathrm{CD}+\mathrm{COR}$ treatments, the expression level of $D B T N B T$ gene (responsible for the conjugation of benzoylCoA to 3'-N-debenzoyl-2'-deoxytaxol) increased by 14, 3.9, and 3.6 times, respectively (Fig. 3 and Table 2).

As far as $A B C$ gene (responsible for paclitaxel secretion) is concerned, pCAM-DBTNBT/CD+COR ranked first, followed by PCAM and CD+COR, respectively (Fig. 3 and Table 2).

\section{Discussion}

Cell suspension culture is known as one of the most adaptable methods for taxol production in Taxus species, in which the amounts of the produced paclitaxel can be expanded to a limited extent using different elicitors. This constraint is closely related to the function of rate-limiting enzymes (Exposito et al. 2010; Ho et al. 2005). In this study, overexpression of the DBTNBT gene together with CD and COR dual elicitation compared to the other treatments ( $\mathrm{PCAM}, \mathrm{CD}+\mathrm{COR}$, and no-inoculation/no-elicitation control) led to some impacts on the expression level of paclitaxel involved genes and taxol production.

The expression profile of $T 13 a H$ indicated that the combined use of DBTNBT overexpression and dual elicitation with $\mathrm{CD}$ and COR did not significantly affect the $T 13 a H$ expression level, probably because bottleneck removal affects the expression level of genes involved in the downstream region of the paclitaxel biosynthetic pathway.

Comparing the $T 13 a H$ fold-changes in pCAM-DBTNBT/CD+COR and PCAM treatments showed that the relative increase in the expression level was probably due to Agrobacterium inoculation, not the increased expression level of $D B T N B T$ gene. This finding is in accordance with that reported in the research conducted on the overexpression of TXS in Taxus cells inoculated by A. rhizogenes (Exposito et al. 2010).

The relative expression level of $T 14 \beta H$ showed a decrease, which is considered to be highly favorable because of the essential role of the $T 14 \beta H$ gene in the paclitaxel biosynthetic pathway towards undesirable taxanes (Li et al. 2011). 
The expression profile of the $D B A T$ gene indicates that this gene's expression level is affected by the impacts of inoculation with Agrobacterium containing pCAMBIA1304 and the Agrobacterium containing pCAMBIA-DBTNBT vector. The comparative analysis of the treatments showed that the increase in DBAT expression level was partly because of Agrobacterium inoculation.

According to the results, $C D$ and COR were not highly effective in increasing the expression level of $D B A T$ gene. This is consistent with the results of other studies in which the expression level of DBAT gene was not significantly affected by the effects of the elicitors (Kashani et al. 2018; Onrubia et al. 2011; Sah et al. 2019). However, the inoculation with Agrobacterium harboring pCAMBIA1304 proved to be effective in removing the $D B A T$ bottleneck. Comparing the results of this research to those of other studies, using potent elicitors, such as CD and COR, revealed the potential of Agrobacterium in the relative removal of the $D B A T$ bottleneck. This finding is in line with the results of Exposito et al., who concluded that the TDNA of the $A$. rhizogenes (wild type) was able to significantly increase the expression level of $T X S$ gene along with taxane production in Taxus cells (Exposito et al. 2010).

The BAPT expression level increased (up to 6.4-fold) in pCAM-DBTNBT/CD+COR treatment. Nonetheless, the inoculation by Agrobacterium containing the pCAMBIA1304 vector resulted in a 4.9 fold-change in the expression level of the BAPT gene. Elicitation by $C D$ and COR showed no remarkable increase in the expression level of this gene; thus, it could be concluded that the Agrobacterium transformation may be a powerful alternative (even more potent than $\mathrm{CD}$ and COR elicitation) for inducing BAPT expression in $T$. baccata leaves. Meanwhile, the higher increase in BAPT expression level in $T$. baccata leaves, inoculated with pCAMBIA-DBTNBT vector rather than pCAMBIA1304, confirmed that the DBTNBT gene is one of the main bottlenecks in the paclitaxel biosynthetic pathway because $D B T N B T$ overexpression increases the expression level of other downstream-involved genes, such as BAPT. Unquestionably, the increase in paclitaxel amounts caused by DBTNBT overexpression in T. baccata confirmed this hypothesis.

The results also indicated that the combined use of $C D$ and COR was not highly effective in increasing the expression level of BAPT gene. These findings are in accordance with those of previous studies (Kashani et al. 2018; Ramirez-Estrada et al. 2015), in which BAPT was recognized as a bottleneck gene in paclitaxel biosynthetic pathway. The results of the current experiment, in line with those of another study (Exposito et al. 2010), revealed that Agrobacterium harboring pCAMBIA1304 was much more effective than $\mathrm{CD}$ and $\mathrm{COR}$ regarding the relative removal of $B A P T$ bottleneck.

The results implied that the overexpression of $D B T N B T$ gene associated with dual elicitation compared to the Agrobacterium inoculation had higher effects on the expression level of $A B C$ gene. Therefore, the inoculation of $T$. baccata leaves with Agrobacterium could be considered as an incredibly effective approach to increasing the expression level of the $A B C$ gene. $C D$ and COR were not able to significantly increase the $A B C$ expression level, which is consistent with the results of previous studies (Kashani et al. 2018; Sabater-Jara et al. 2010).

The results of $D B A T, B A P T$, and $A B C$ expression level indicated that the combined use of transient overexpression and $C D$ and $C O R$ dual elicitation was much more effective than that of individual 
elicitation. This result is in line with the findings of other researchers (Exposito et al. 2010; Ho et al. 2005).

To sum up, the expression levels of $D B A T, B A P T$, and $A B C$ genes significantly increased because of the Taxus leaves inoculation via Agrobacterium harboring no paclitaxel pathway involved gene. This result is probably due to the role of Agrobacterium as a pathogen and the function of paclitaxel in Taxus spp. defense mechanism (Bentebibel et al. 2005; Collin 2001; Li et al. 2012; M. Cusidó et al. 2002; Onrubia. et al. 2013). Furthermore, the amount of paclitaxel produced in the CD+COR treatment, despite the lower expression level of paclitaxel involved genes compared with the pCAM treatment, ranked second. It was presumably due to the elicitation effects of CD and COR (Kashani et al. 2018; Ramirez-Estrada et al. 2015 ) in addition to the role of $C D$ in the complex formation with hydrophobic compounds and the secretion of cell-derived paclitaxel (Bru et al. 2006; Ramirez-Estrada et al. 2015; Ramirez-Estrada et al. 2016). The paclitaxel measurement indicated that although the increased relative expression level of the $A B C$ gene augmented the extracellular paclitaxel amounts, the increase was not significant and that the elicitation with CD played a vital role in paclitaxel secretion (Fig. 2 and Fig. 3).

Based on the results, the $D B T N B T$ overexpression probably leads to related substrate catalysis; this seemingly reduces the feedback repression of this substrate on the TBT, COA Ligase, and BAPT genes, resulting in the production of more paclitaxel (Cusido et al. 2014). The CD complex formation with paclitaxel and the increased expression level of $A B C$ gene culminated in paclitaxel secretion to the extracellular medium, reduced paclitaxel feedback repression on the upstream genes, and the inhibition of extracellular paclitaxel degradation.

\section{Conclusions}

DBTNBT overexpression associated with $\mathrm{CD}$ and COR elicitation contributed to much more paclitaxel production and the prevention of feedback repression on the upstream bottleneck genes, such as DBAT and $B A P T$. The results of this study revealed that Taxus metabolic engineering, along with elicitation, is able to produce noticeable amounts of paclitaxel to meet its increasing demand in the foreseeable future.

\section{Abbreviations}

MeJA: Methyl jasmonate; COR: Coronatine; CD: Methyl- $\beta$-cyclodextrin; GAPDH. Glyceraldehyde-3phosphate dehydrogenase; TXS. Taxadiene synthase; T13aH. Taxane 13a-hydroxylase; T14ßH. Taxane 14ß-hydroxylase; TBT: Taxane-2a-O-benzoyl transferase; DBAT: 10-deacetylbaccatin III-10-0acetyltransferase; BAPT: Baccatin III-3-amino 13-pheny/propanoyl-CoA transferase; DBTNBT: Debenzoyltaxol N-benzoyl transferase; PAM: Phenylalanine amino mutase; ABC. ATP-binding cassette; ORF: Open Reading Frame; GFP. Green fluorescent protein; GUS. $\beta$ - glucuronidase; OD: Optical Density; SE: Standard Error; CRD: Completely Randomized Design; LSD: Least Significant Difference; CDS: Coding Sequence; CaMV 35S Promoter: Cauliflower Mosaic Virus Promoter; NOS Terminator: Nopaline Synthase Terminator; cDNA: Complementary DNA; HPLC: High- Performance Liquid Chromatography; RP: Reverse Phase; F: Forward Primer;R: Reverse Primer 


\section{Declarations}

\section{Author's contribution statement}

All authors contributed to the study's conception and design. Kimia Kashani performed material preparation, data collection, and analysis. She wrote the first draft of the manuscript and the other authors (Mohammad Sadegh Sabet, Mokhtar Jalali Javaran, and Ahmad Moieni) commented on previous versions of the manuscript. All authors read and approved the final manuscript.

\section{Acknowledgements}

All authors gratefully acknowledge the support of Tarbiat Modares University.

\section{Funding}

No funding was received to assist with the preparation of this manuscript.

\section{Conflicts of interest/ Competing interest}

The authors declare that they have no known competing financial interests or personal relationships that could have appeared to influence the work reported in this paper.

\section{Ethical approval}

Not applicable.

\section{Availability of data and materials}

Data generated or analyzed during this study was included in this paper.

\section{Code availability}

Not applicable.

\section{References}

1. Almagro L, Pedreño M (2020) Use of cyclodextrins to improve the production of plant bioactive compounds. Phytochem Rev 19(4):1061-1080. http:/ doi: 10.1007/s11101-020-09704-6

2. Bender CL, Alarcón-Chaidez F, Gross DC (1999) Pseudomonas syringae phytotoxins: mode of action, regulation, and biosynthesis by peptide and polyketide synthetases. Microbiol Mol Biol Rev 63(2):266-292. http:/. doi

3. Bentebibel S, Moyano E, Palazón J, Cusidó RM, Bonfill M, Eibl R, Pinol MT (2005) Effects of immobilization by entrapment in alginate and scale-up on paclitaxel and baccatin III production in cell suspension cultures of Taxus baccata. Biotechnol bioeng 89(6):647-655. http:/. doi 
4. Bru R, Sellés S, Casado-Vela J, Belchí-Navarro S, Pedreño MA (2006) Modified cyclodextrins are chemically defined glucan inducers of defense responses in grapevine cell cultures. J Agric Food Chem 54(1):65-71. http:/. doi

5. Chandran H, Meena M, Barupal T, Sharma K (2020) Plant tissue culture as a perpetual source for production of industrially important bioactive compounds. Biotechnol Rep 26:e00450. http:/. doi

6. Channuntapipat C, Sedgley M, Collins G (2001) Sequences of the cDNAs and genomic DNAs encoding the S1, S7, S8, and Sf alleles from almond, Prunus dulcis. Theor Appl Genet 103(6-7):11151122. http:/ doi: 10.1007/s001220100629

7. Collin HA (2001) Secondary product formation in plant tissue cultures. Plant Growth Regul 34(1):119-134. http:/. doi

8. Cragg GM, Newman DJ (2005) Plants as a source of anti-cancer agents. J Ethnopharmacol 100(12):72-79. http:/ doi:10.1016/j.jep.2005.05.011

9. Cusido RM, Onrubia M, Sabater-Jara AB, Moyano E, Bonfill M, Goossens A, Pedreño MA, Palazon J (2014) A rational approach to improving the biotechnological production of taxanes in plant cell cultures of Taxus spp. Biotechnol Adv 32(6):1157-1167. HTTP:/ doi:

10.1016/j.biotechadv.2014.03.002

10. Exposito O, Syklowska-Baranek K, Moyano E, Onrubia M, Bonfill M, Palazon J, Cusido RM (2010) Metabolic responses of Taxus media transformed cell cultures to the addition of methyl jasmonate. Biotechnol Prog 26(4):1145-1153. http:/ doi: 10.1002/btpr.424

11. Green R, Rogers EJ (2013) Transformation of chemically competent $E$. coli. Changes 29:329-336

12. Ho C-K, Chang S-H, Lung J, Tsai C-J, Chen K-P (2005) The strategies to increase taxol production by using Taxus mairei cells transformed with TS and DBAT genes. Int J Appl Sci Eng 3(3):179-185

13. Jaziri M, Zhiri A, Guo Y-W, Dupont J-P, Shimomura K, Hamada H, Vanhaelen M, Homès J (1996) Taxus sp. cell, tissue and organ cultures as alternative sources for taxoids production: a literature survey. Plant Cell Tissue Organ Cult 46(1):59-75. http:/. doi:10.1007/BF00039697

14. Jennewein S, Rithner CD, Williams RM, Croteau RB (2001) Taxol biosynthesis: taxane 13ahydroxylase is a cytochrome P450-dependent monooxygenase. Proc Natl Acad Sci 98(24):1359513600. http:/. doi

15. Kashani K, Jalali Javaran M, Sabet MS, Moieni A (2018) Identification of rate-limiting enzymes involved in paclitaxel biosynthesis pathway affected by coronatine and methyl- $\beta$-cyclodextrin in Taxus baccata L. cell suspension cultures. Daru 26(2):129-142. http:/. doi:10.1007/s40199-0180217-1

16. Li F-L, Ma X-J, Hu X-L, Hoffman A, Dai J-G, Qiu D-Y (2011) Antisense-induced suppression of taxoid 14ß-hydroxylase gene expression in transgenic Taxus $\times$ media cells. Afr J Biotechnol 10(44):87208728

17. Li S-t, Zhang P, Zhang M, Fu C-h, Zhao C-f, Dong Y-s, Guo A-y, Yu L-j (2012) Transcriptional profile of Taxus chinensis cells in response to methyl jasmonate. BMC Genomics 13(1):295. http:/. doi 
18. Lijavetzky D, Almagro L, Belchi-Navarro S, Martínez-Zapater JM, Bru R, Pedreño MA (2008) Synergistic effect of methyljasmonate and cyclodextrin on stilbene biosynthesis pathway gene expression and resveratrol production in Monastrell grapevine cell cultures. BMC Res Notes 1(1):132. http:/. doi

19. Livak KJ, Schmittgen TD (2001) Analysis of relative gene expression data using real-time quantitative PCR and the $2^{-\triangle \Delta C T}$ method. methods 25(4):402-408. http:/ doi:

$10.1006 /$ meth.2001.1262

20. Cusidó M, Palazón R, Bonfill J, Navia-Osorio M, Morales A, Piñol MT (2002) Improved paclitaxel and baccatin III production in suspension cultures of Taxus media. Biotechnol Prog 18(3):418-423. http:/ doi: 10.1021/bp0101583

21. Malik S, Cusidó RM, Mirjalili MH, Moyano E, Palazón J, Bonfill M (2011) Production of the anticancer drug taxol in Taxus baccata suspension cultures: a review. Process Biochem 46(1):23-34. http:/. doi

22. Mubeen S, He C-T, Asad BA, Yang Z-Y (2019) Overview of past and present developments towards biotechnological and molecular approaches to improve taxol production. Frontiers in Natural Product Chemistry: Volume 5 5:95-145

23. Onrubia M, Cusidó R, Ramirez K, Hernández-Vázquez L, Moyano E, Bonfill M, Palazon J (2013) Bioprocessing of plant in vitro systems for the mass production of pharmaceutically important metabolites: paclitaxel and its derivatives. Curr Med Chem 20(7):880-891. http:/. doi

24. Onrubia M, Moyano E, Bonfill M, Palazon J, Goossens A, Cusido RM (2011) The relationship between $T X S, D B A T, B A P T$ and $D B T N B T$ gene expression and taxane production during the development of Taxus baccata plantlets. Plant sci 181(3):282-7. http:/ doi:10.1016/j.plantsci.2011.06.006

25. Onrubia., Moyano E, Bonfill M, Cusido RM, Goossens A, Palazon J (2013) Coronatine, a more powerful elicitor for inducing taxane biosynthesis in Taxus media cell cultures than methyl jasmonate. J Plant Physiol 170(2):211-9. http:/. doi:10.1016/j.jplph.2012.09.004

26. Pyo SH, Song BK, Ju CH, Han BH, Choi HJ (2005) Effects of absorbent treatment on the purification of paclitaxel from cell cultures of Taxus chinensis and yew tree. Process Biochem 40(3):1113-1117. http:/. doi

27. Rahpeyma SA, Moieni A, Jalali Javaran M (2015) Paclitaxel production is enhanced in suspensioncultured hazel (Corylus avellana L.) cells by using a combination of sugar, precursor, and elicitor. Eng Life Sci 15(2):234-242. http:/ doi: 10.1002/elsc.201400115

28. Ramirez-Estrada K, Osuna L, Moyano E, Bonfill M, Tapia N, Cusido RM, Palazon J (2015) Changes in gene transcription and taxane production in elicited cell cultures of Taxus $\times$ media and Taxus globosa. Phytochemistry. http:/ 117:174-184 doi: 10.1016/j.phytochem.2015.06.013

29. Ramirez-Estrada K, Vidal-Limon H, Hidalgo D, Moyano E, Golenioswki M, Cusidó RM, Palazon J (2016) Elicitation, an effective strategy for the biotechnological production of bioactive high-added value compounds in plant cell factories. Molecules 21(2):182. http:/. doi

30. Sabater-Jara AB, Tudela LR, López-Pérez AJ (2010) In vitro culture of Taxus sp.: strategies to increase cell growth and taxoid production. Phytochem Rev 9(2):343-356. http: doi:10.1007/s11101- 
010-9167-z

31. Sabater-Jara AB, Onrubia M, Moyano E, Bonfill M, Palazón J, Pedreño MA, Cusidó RM (2014) Synergistic effect of cyclodextrins and methyl jasmonate on taxane production in Taxus $\mathrm{x}$ media cell cultures. Plant Biotechnol J 12(8):1075-1084. http:/. doi

32. Sabzehzari M, Naghavi M (2019) Phyto-miRNAs-based regulation of metabolites biosynthesis in medicinal plants. Gene 682:13-24. http:/ doi: 10.1016/j.gene.2018.09.049

33. Sah B, Subban K, Jayabaskaran C (2019) Biochemical insights into the recombinant 10deacetylbaccatin III-10- $\beta-0$-acetyltransferase enzyme from the Taxol-producing endophytic fungus Lasiodiplodia theobromae. FEMS Microbiol Lett 366(7):fnz072. http:/. doi

34. Salehi M, Naghavi MR, Bahmankar M (2019) A review of Ferula species: Biochemical characteristics, pharmaceutical and industrial applications, and suggestions for biotechnologists. Ind Crops Prod 139:111511. http:/. doi

35. Sambrook J, Russell D (2001) Molecular cloning: a laboratory manual. Cold Spring Harb Lab Press Cold Spring Harb NY 999

36. Satish L, Shamili S, Yolcu S, Lavanya G, Alavilli H, Swamy MK (2020) Biosynthesis of secondary metabolites in plants as influenced by different factors Plant-derived Bioactives. Springer, pp 61-100

37. Singh M, Poddar NK, Singh D, Agrawal S (2020) Foliar application of elicitors enhanced the yield of withanolide contents in Withania somnifera (L.) Dunal (variety, Poshita). 3 Biotech 10(4):1-8. http:/. doi

38. Srivastava V, Negi AS, Kumar J, Gupta M, Khanuja SP (2005) Plant-based anticancer molecules: a chemical and biological profile of some important leads. Bioorg Med Chem 13(21):5892-5908. http:/ doi.org/10.1016/j.bmc.2005.05.066

39. Zamboni A, Gatto P, Cestaro A, Pilati S, Viola R, Mattivi F, Moser C, Velasco R (2009) Grapevine cell early activation of specific responses to DIMEB, a resveratrol elicitor. BMC Genomics 10(1):363. http:/. doi

40. Zhao Y, Thilmony R, Bender CL, Schaller A, He SY, Howe GA (2003) Virulence systems of Pseudomonas syringae pv. tomato promote bacterial speck disease in tomato by targeting the jasmonate signaling pathway. Plant J 36(4):485-499. http:/. doi

41. Zhu L, Chen L (2019) Progress in research on paclitaxel and tumor immunotherapy. Cell Mol Biol Lett 24(1):1-11. http:/ doi: 10.1186/s11658-019-0164-y

\section{Figures}




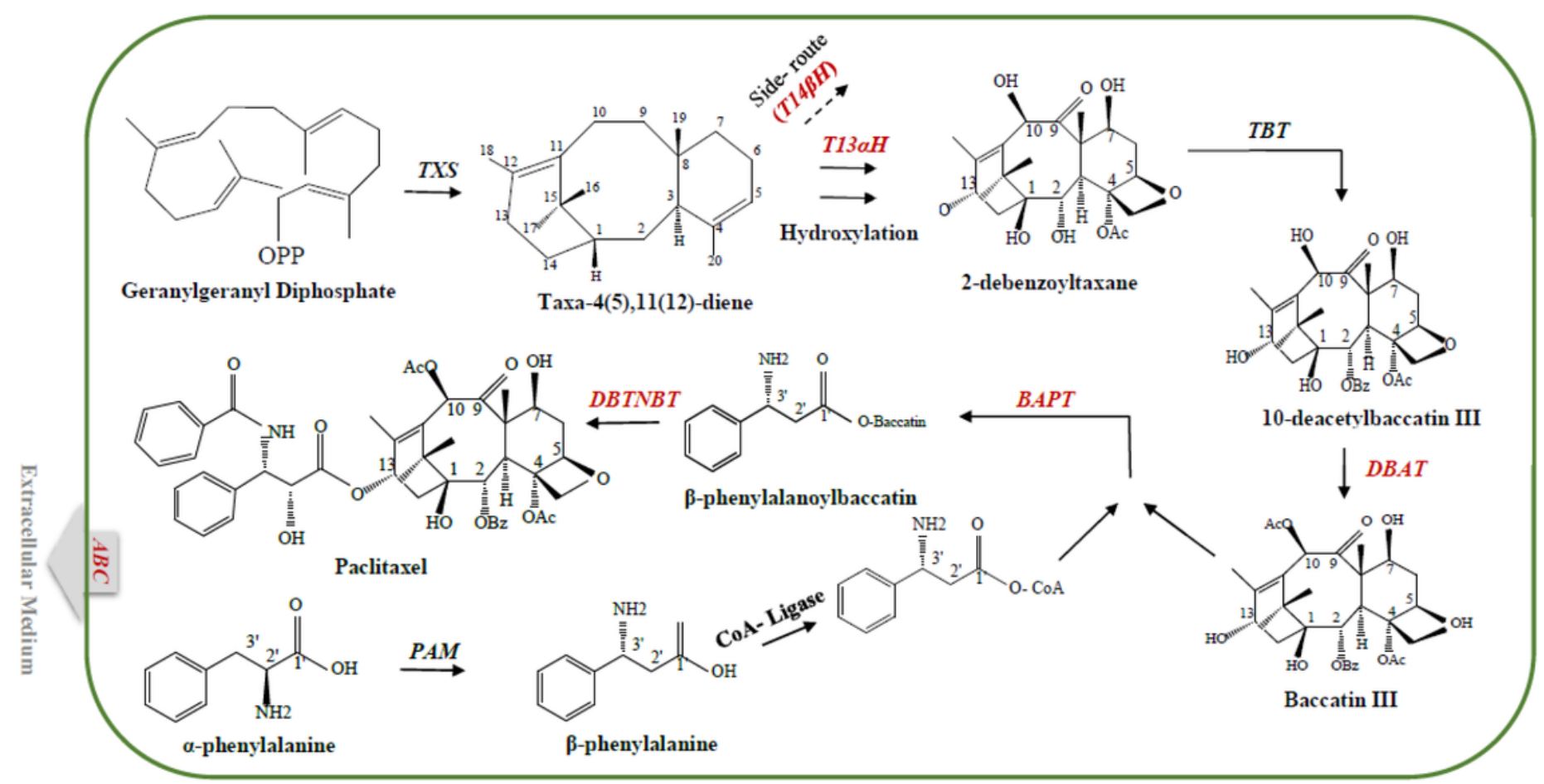

Figure 1

A summarized paclitaxel biosynthesis pathway TXS, taxadiene synthase; $T 13 a \mathrm{H}$, taxane $13 \mathrm{a}-$

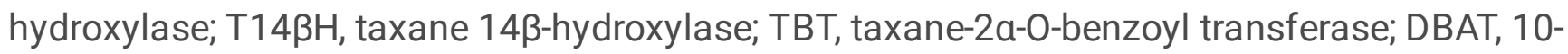
deacetylbaccatin III-10-0-acetyltransferase; BAPT, baccatin III-3-amino 13-phenylpropanoyl- CoA transferase; DBTNBT, debenzoyltaxol N-benzoyl transferase; PAM, phenylalanine amino mutase; CoA Ligase, and ABC, ATP-binding cassette. Colored gene names point out to the genes that have been investigated in this research 


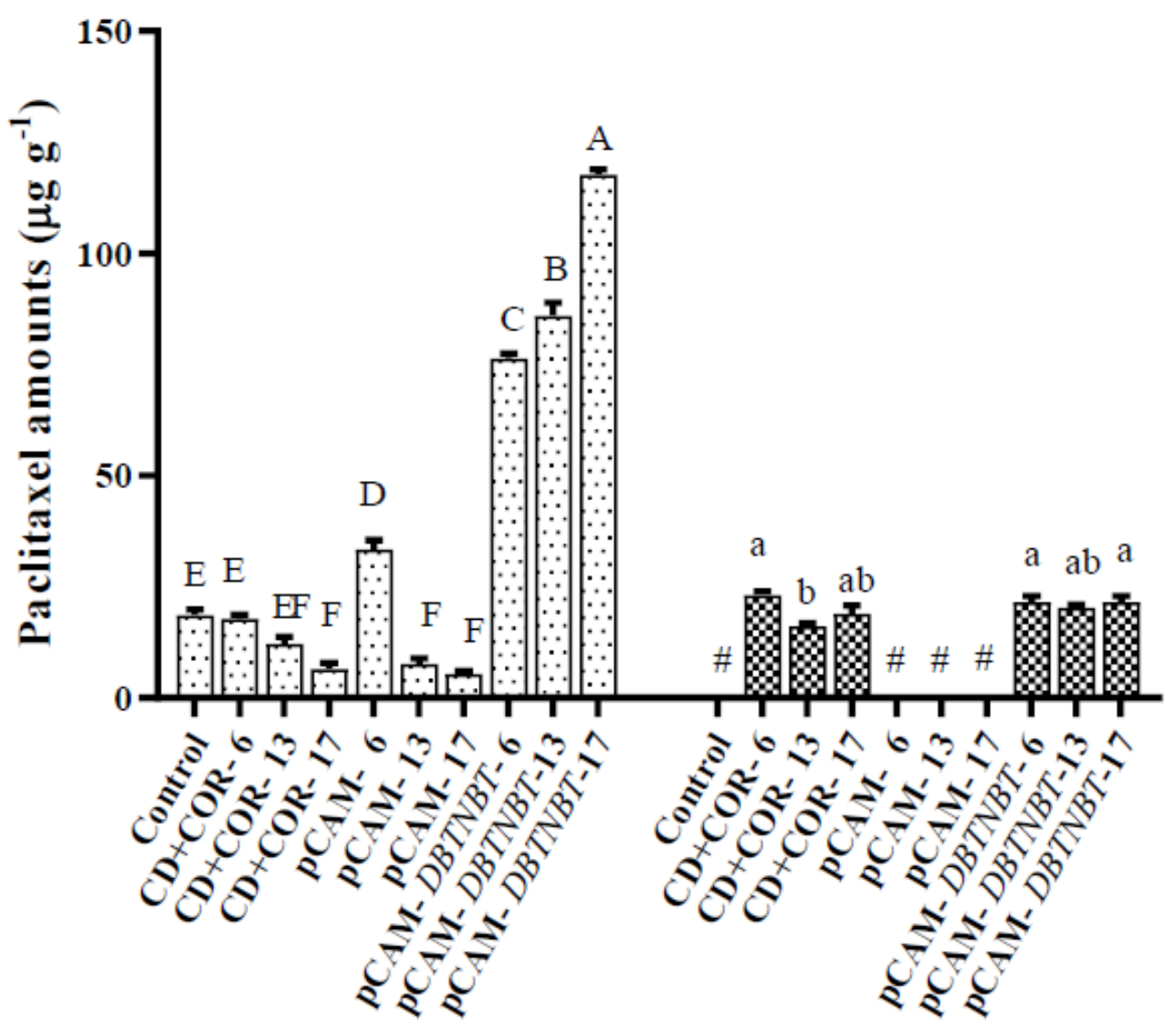

Figure 2

The comparison of cell-associated and extracellular paclitaxel amounts in Taxus baccata leaves The value of each column represents the average of at least two biological and two technical replications \pm SE. Upper and lower cases represent the results of LSD mean comparison test ( $P$-value $<0.01)$ performed on cell-associated and extracellular paclitaxel contents in different treatments, respectively. Means with at least one common letter did not show any significant difference. \#) not detected. Different treatments were as follows: Control, no-inoculation/no-elicitation control; CD+COR- 6,13 , and 17, no inoculationelicitation with methyl- $\beta$ - cyclodextrin (CD) and coronatine (COR) 6,13 , and 17 days after elicitation; pCAM- 6,13 , and 17, inoculation with Agrobacterium harboring PCAMBIA1304 vector- no elicitation (equivalent to 6,13 , and 17 days after elicitation); PCAM-DBTNBT- 6,13 , and 17, inoculation with Agrobacterium harboring pCAMBIA1304-DBTNBT vector- elicitation with methyl- $\beta$ - cyclodextrin (CD) and coronatine (COR) 6, 13, and 17 days after elicitation 

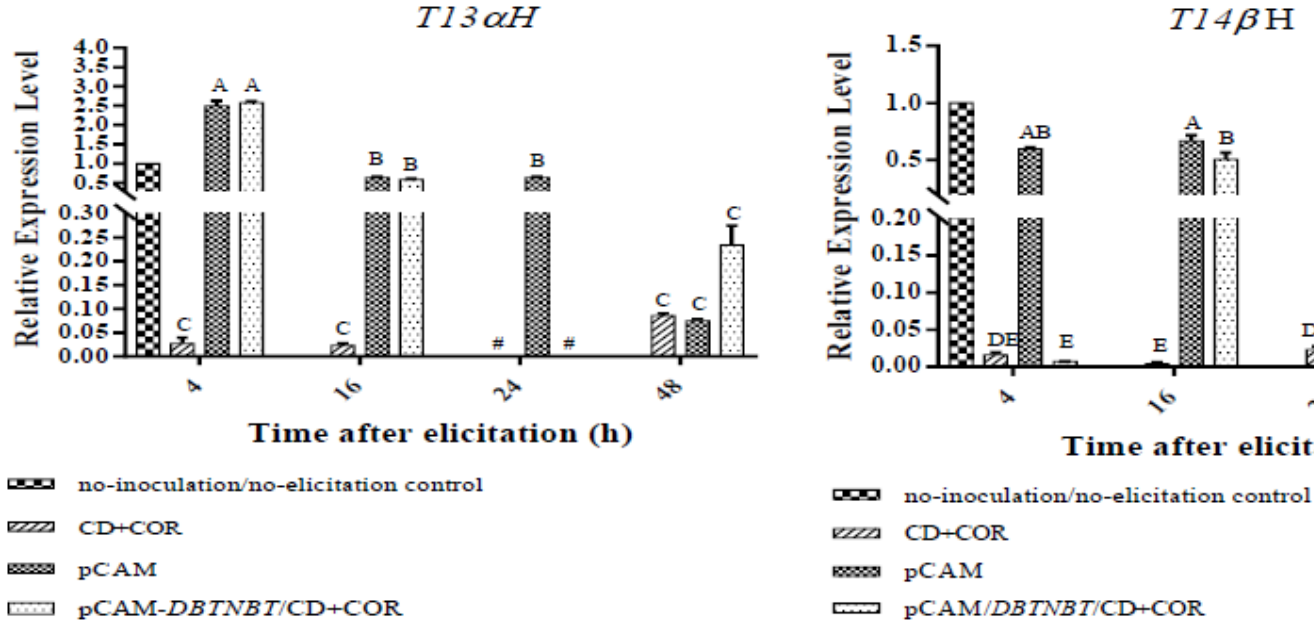

$\square$ no-inoculation/no-elicitation control
CD+COR
pCAM
pCAM-DBTNBT/CD+COR

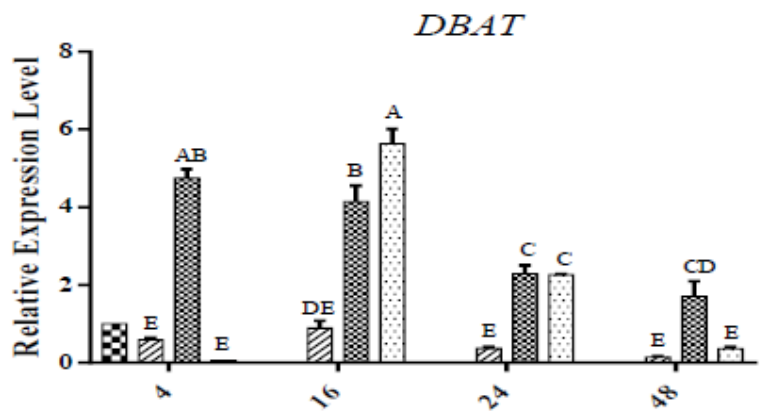

Time after elicitation (h)

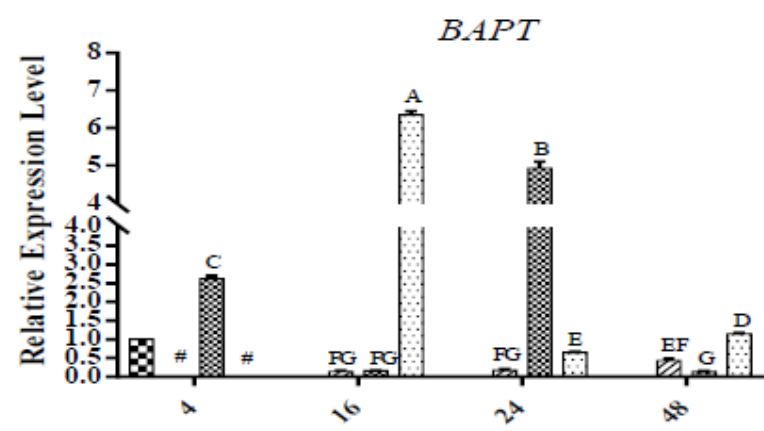

Time after elicitation (h)

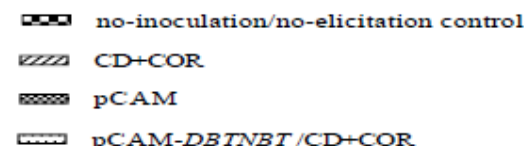

$D B T N B T$

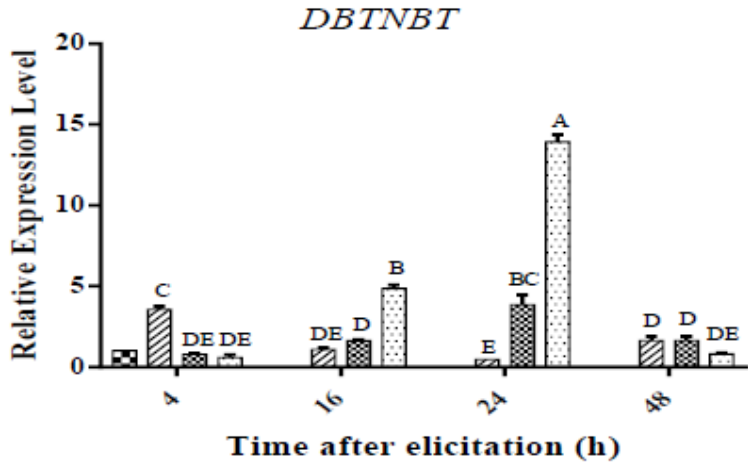

00 no-inoculation/no-elicitation control

2IA $\mathrm{CD}+\mathrm{COR}$

$\$ 20 \times$ PCAM

$\mathrm{pCAM}-D B T N B T / C D+C O R$

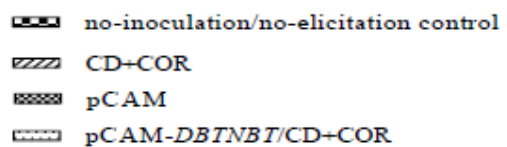

$A B C$

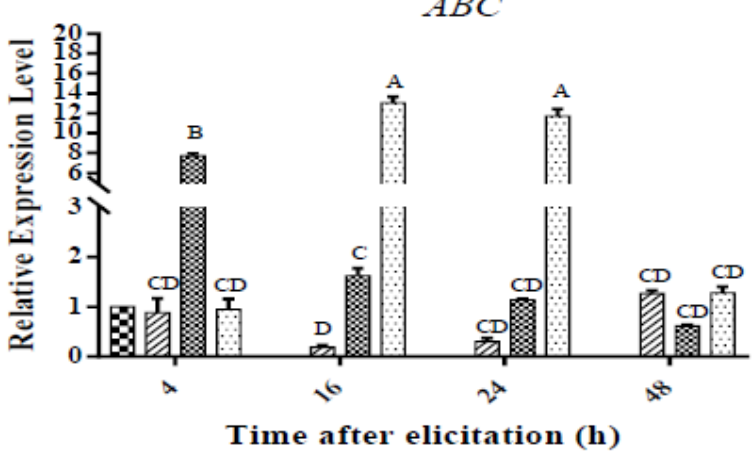

no-inoculation/no-elicitation control

ए2य $\mathrm{CD}+\mathrm{COR}$

$\because 6 \infty \mathrm{PCAM}$

$\mathrm{pCAM}-D B T N B T / C D+\mathrm{COR}$

\section{Figure 3}

The relative expression levels of $\mathrm{T} 13 \mathrm{aH}, \mathrm{T} 14 \mathrm{BH}$, DBAT, BAPT, DBTNBT and ABC genes in Taxus baccata leaves treated differently, including no-inoculation/no-elicitation control, $\mathrm{CD}+\mathrm{COR}$ (no inoculationelicitation with methyl- $\beta$ - cyclodextrin (CD) and coronatine (COR)), pCAM (inoculation with Agrobacterium harboring pCAMBIA1304 vector- no elicitation), and pCAM-DBTNBT/CD+COR (inoculation with Agrobacterium harboring pCAMBIA1304-DBTNBT vector- elicitation with methyl- $\beta$ - cyclodextrin (CD) 
and coronatine (COR)) Horizontal axis) Times after elicitation by CD and COR. Vertical axis) The expression level of $\mathrm{T} 13 \mathrm{aH}, \mathrm{T} 14 \beta \mathrm{H}, \mathrm{DBAT}, \mathrm{BAPT}, \mathrm{DBTNBT}$, and ABC genes relative to the expression level of GAPDH as a reference gene compared to the no-inoculation/no-elicitation control, $4 \mathrm{~h}$ after elicitation time. \#) not detected. Each column's value represents the mean of at least two biological and two technical repetitions \pm SE. The letters represent the results of LSD mean comparison test (P-value $<0.01)$ performed on different treatments, and means with at least one common letter did not show any significant difference

\section{Supplementary Files}

This is a list of supplementary files associated with this preprint. Click to download.

- GraphicalAbs.1400.docx

- Supp.Material.docx 